Does the quality of learning outcomes fall when education expands to include more disadvantaged students?

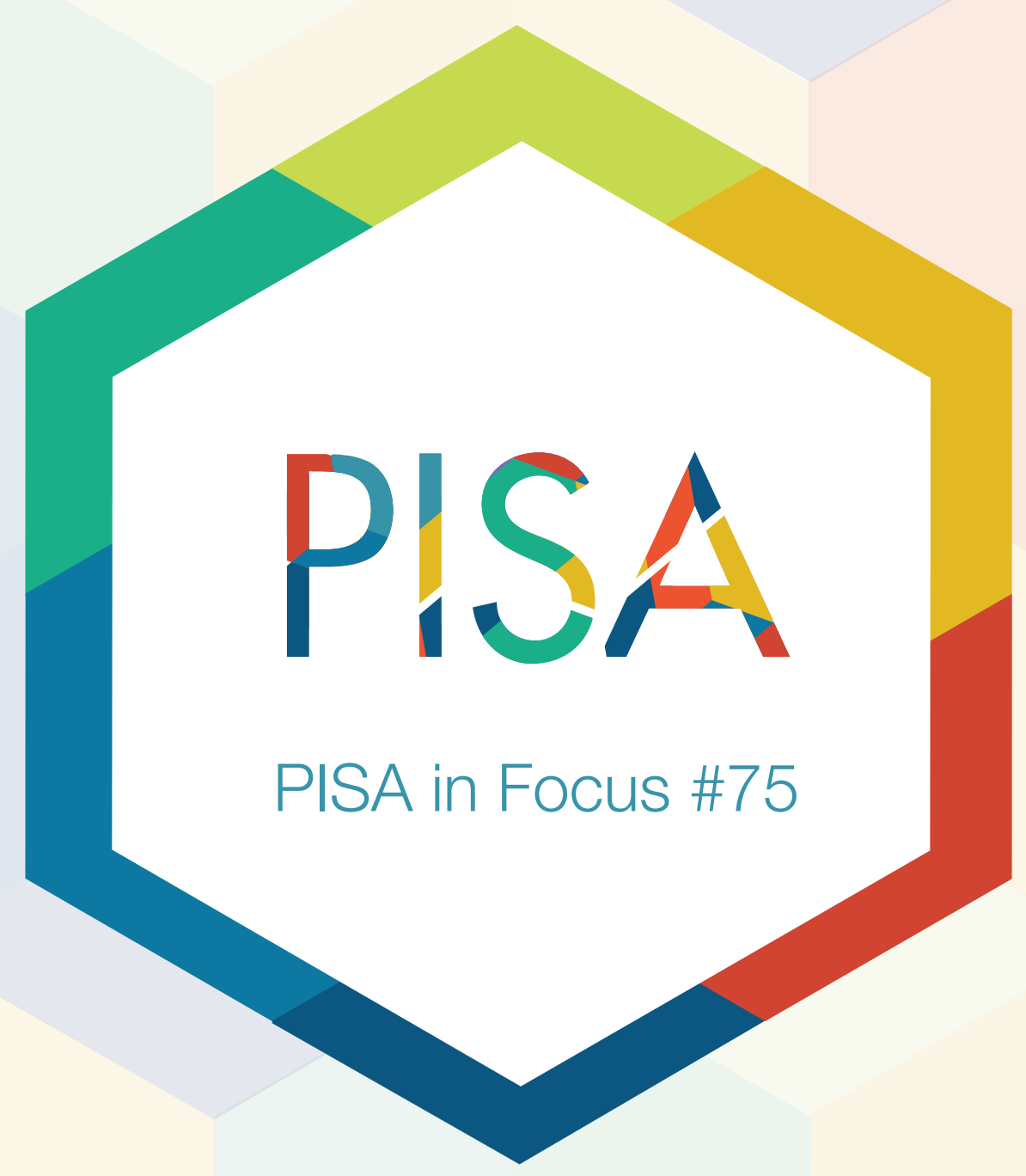




\section{Does the quality of learning outcomes fall when education expands to include more disadvantaged students?}

- When Albania, Brazil, Colombia, Costa Rica, Indonesia, Jordan, Mexico, Turkey and Uruguay first participated in PISA, fewer than two in three 15-year-olds were eligible to sit the test. But thanks to the rapid growth in secondary enrolment rates over recent years, by 2015 the students in these countries assessed by PISA had become more representative of their age group.

- The experience of these nine countries shows that increases in access to schooling have not, in general, come at the expense of the average quality of education for 15 -year-olds.

- In Albania, Brazil, Colombia, Indonesia, Jordan, Mexico and Turkey, the level of mathematics proficiency attained by the top quarter of 15-year-olds increased significantly over years in which education expanded to include more disadvantaged children, showing that advantaged children can also benefit when more of their peers have access to education.

When PISA 2015 chose the schools and students that would take the test, not all children born in 1999 were included in the lists from which the participants were drawn. In fact, 15-year-olds had to meet an additional condition to participate in PISA on top of a birth date in 1999: being enrolled in school at the time of testing, in $7^{\text {th }}$ grade or higher (in some countries that tested students in the second part of 2015, a 12-month period spanning the years 1999 and 2000 defined the eligible birthdates).

This condition might sound almost redundant in many OECD countries. But because eligibility in PISA is determined by more than just a date of birth, in many low- and middle-income countries the PISA sample does not necessarily represent the entire population of 15-year-olds. PISA results thus reflect a combination of 15-year-olds' access to education and the quality of education that they have received up to that point.

\section{Access to education has expanded enormously.}

Globally, enrolment in secondary education has expanded dramatically over the past decades. This expansion is also reflected in PISA data, particularly for low- and middle-income countries. Between 2003 and 2015, Indonesia added more than 1.1 million students, Turkey and Brazil more than 400000 students, and Mexico more than 300000 students, to the total population of 15-year-olds eligible to participate in PISA. In Turkey and Brazil, over the same period the total number of 15-year-olds in the country shrank; while in Indonesia and Mexico, the increase in enrolment far outpaced the contemporaneous growth in the population of 15-yearolds. As a result, the PISA coverage - the number obtained by dividing the number of PISA-eligible students by the total number of 15-year-olds in a country - increased greatly in all four countries, and most spectacularly so in Turkey (from 36\% in 2003 to 70\% in 2015). Large increases in coverage were also observed in Albania, Colombia, Costa Rica, Jordan and Uruguay - all countries in which fewer than two out of three 15-year-olds were represented by PISA samples when their country first participated in PISA.

Several factors contributed to lowering the social, economic or institutional barriers that had kept a large proportion of 15-year-olds out of school. Some countries, such as Brazil and Turkey, raised the age at which students can leave compulsory education to over 15; many countries also introduced or strengthened support for at-risk families (e.g. in the form of conditional or unconditional cash transfers); and the rapid change of the economy and increased urbanisation observed in these countries may also have played a role. 
Change in the percentage of 15-year-olds covered by PISA

Selected countries; 2003 or earliest available year to 2015

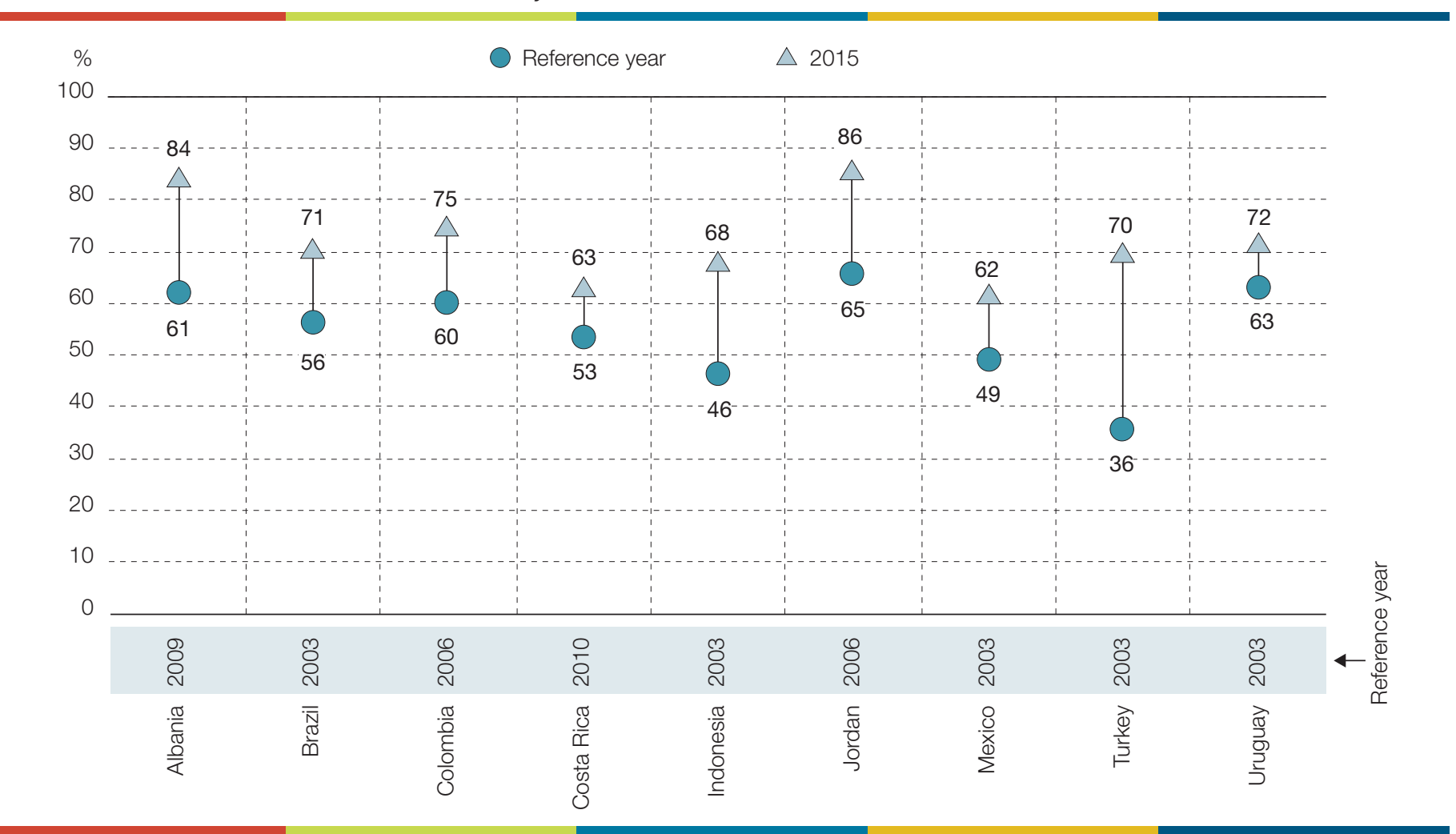

Source: OECD, PISA 2015 Database, Table I.6.1.

This welcome expansion in education opportunities makes it more difficult to interpret how mean scores in PISA have changed over time. Indeed, increases in coverage can lead to an underestimation of the real improvements that education systems have achieved. Household surveys often show that children from poor households, ethnic minorities or rural areas face a greater risk of not attending or completing lower secondary education. Typically, as populations that had previously been excluded gain access to higher levels of schooling, a larger proportion of low-performing students will be included in PISA samples.

\section{Perhaps surprisingly, the expansion of access to education has often been accompanied by improvements in mean PISA performance.}

The experience of Albania, Brazil, Colombia, Costa Rica, Indonesia, Jordan, Mexico, Turkey and Uruguay however shows that increases in access to schooling have not, in general, come at the expense of the average quality of education that 15 -year-olds receive. In fact, Albania and Colombia significantly improved their students' average performance in PISA in all three core PISA subjects - science, reading and mathematics - between their first participation in PISA (2001 for Albania, 2006 for Colombia) and 2015 (science results can be compared back to 2006, mathematics results back to 2003, at best). Indonesia, a PISA participant since 2001, improved its mean results in reading and mathematics, and maintained stable trends in science performance throughout its participation in PISA. Mean results in Brazil and Mexico improved in mathematics and remained stable in reading and science; and Turkey's and Uruguay's mean performance in 2015 is close to that observed in 2003, the first year these countries participated in PISA. Only Costa Rica and Jordan saw some significant declines in their average performance over their participation in PISA, and only in one subject; in Costa Rica, reading performance declined between 2010 and 2015, and in Jordan, science scores fell between 2006 and 2015. 
And all but two countries (Costa Rica and Uruguay) saw improvements in the level of mathematics proficiency attained by the top quarter of 15 -year-olds. By considering a population equal in size to $25 \%$ of an age group, made up of only the best-performing students in a country, it is possible to monitor the rate of change in PISA performance for a sample of 15-year-olds that is barely affected by changes in coverage rates over a given period. This analysis shows that the minimum scores observed among this $25 \%$ of top-performing youth increased rapidly (by more than 20 points per three-year period) in Albania and Turkey, and by about 10 points per three-year period in Brazil, Colombia, Indonesia and Mexico. It also increased by about four points per three-year period in Jordan. This shows that when more disadvantaged children gain access to education for the first time, the remaining students can also benefit.

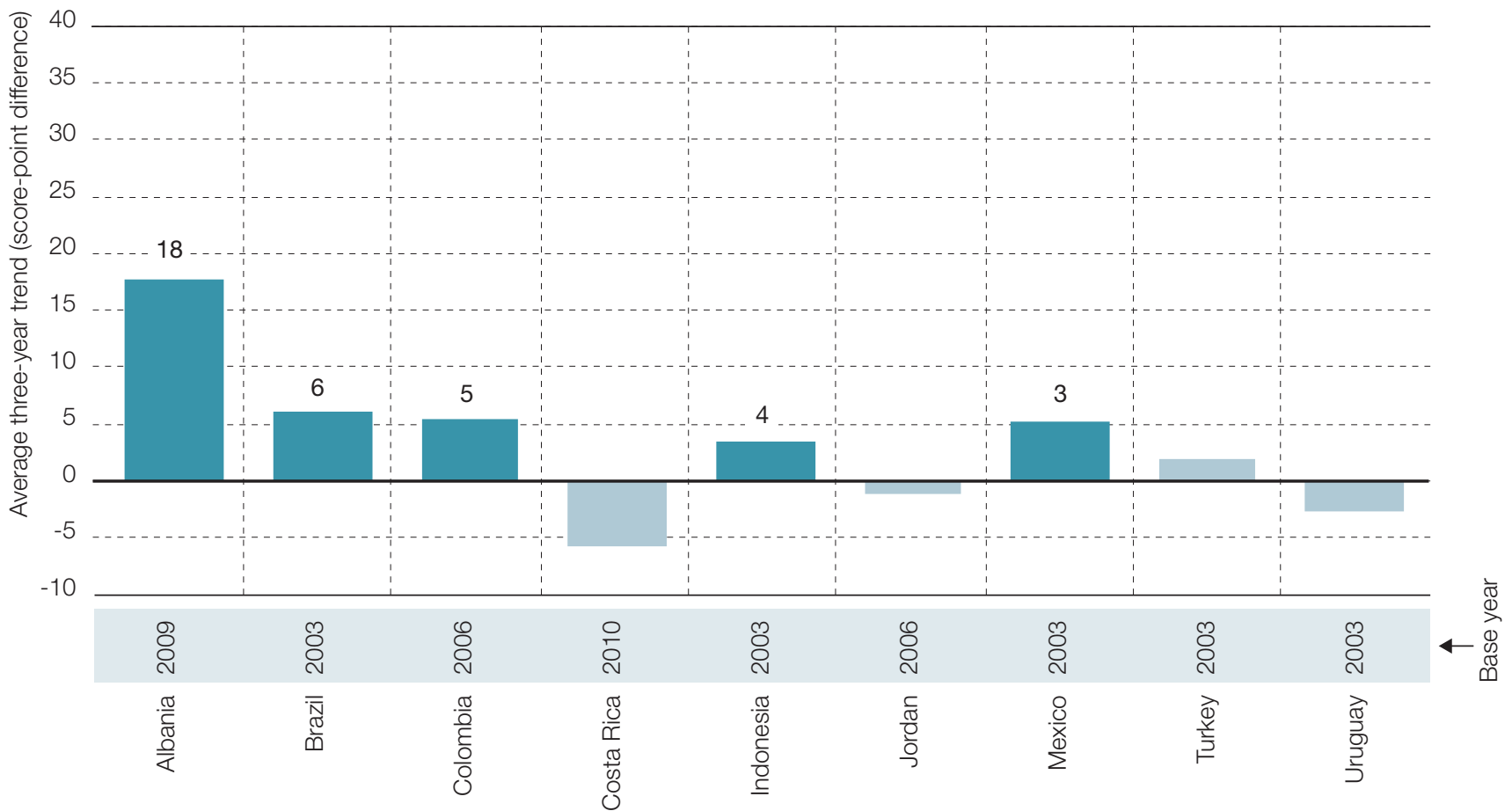

Notes: Statistically significant trends are shown in a darker tone.

The average three-year trend is the average rate of change, per three-year period, between the earliest available measurement in PISA and PISA 2015. Source: OECD, PISA 2015 Database, Table I.5.4a.

Despite these positive findings, the goal of universal enrolment in lower- and upper-secondary education is still far from a reality worldwide. According to UNESCO, in 2014, 34\% of children of lower secondary school age in sub-Saharan Africa and 20\% in South and West Asia were out of school. In PISA 2015, relatively narrow coverage was observed in Viet Nam (49\%), Mexico (62\%), Costa Rica (63\%) and Beijing-Shanghai-Jiangsu-Guangdong (China) (64\%). More low- and middle-income countries are already participating in PISA as part of the PISA for Development initiative, whose data collection, taking place in 2017-18, includes a pilot project to assess the skills of out-of-school children. 


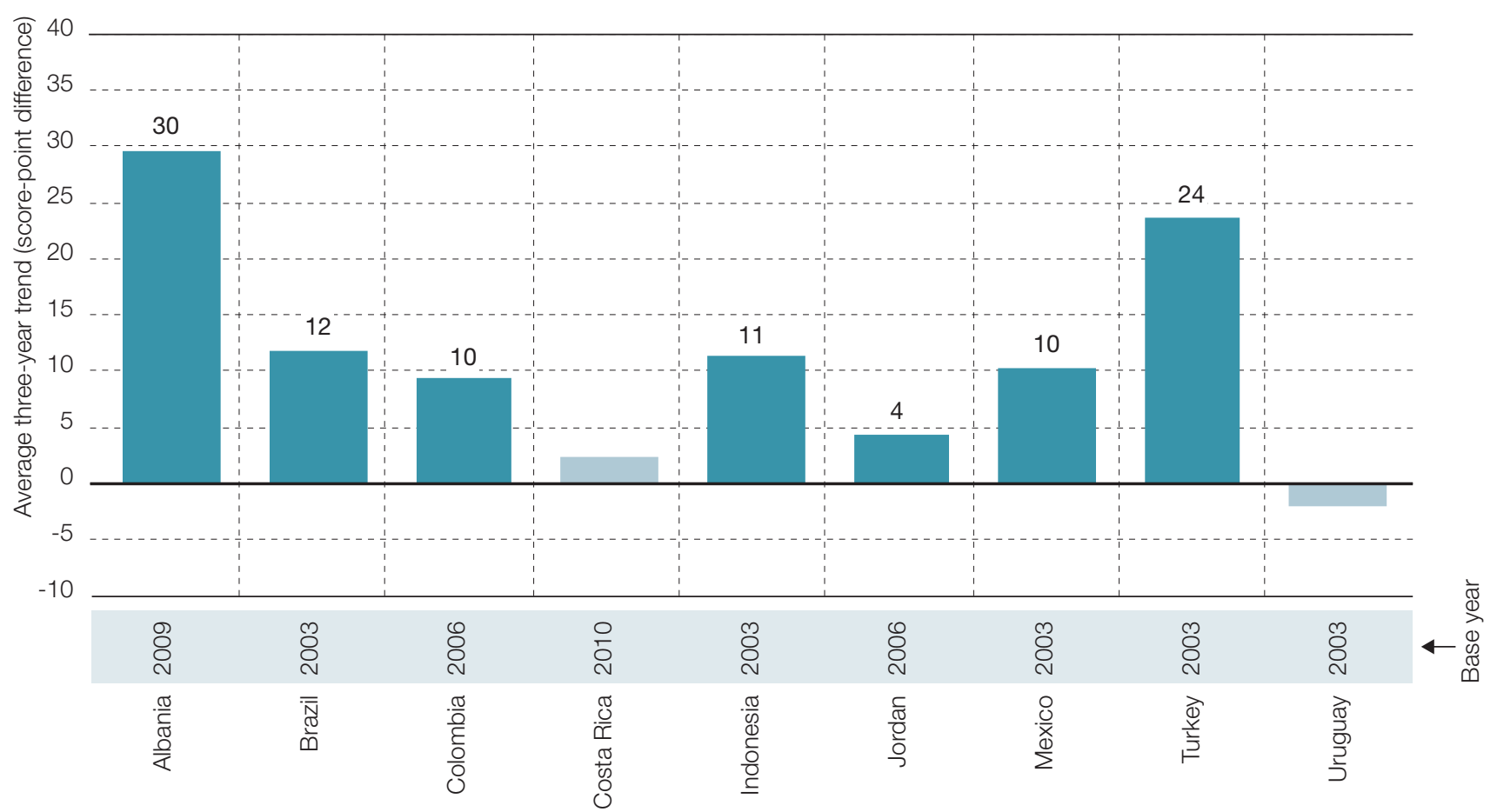

Notes: Statistically significant trends are shown in a darker tone.

The average three-year trend is the average rate of change, per three-year period, between the earliest available measurement in PISA and PISA 2015.

Source: OECD, PISA 2015 Database, Tables I.5.4d.

\section{The bottom line}

Having all 15-year-olds enrolled in school is the first step towards building an inclusive education system; but more schooling does not guarantee that every student will learn. The trends observed in PISA, however, show that greater inclusion and better quality can go hand in hand in low- and middle-income countries, when the quality of learning is assessed. While dismantling the barriers to schooling, countries can also help every student acquire the skills they need to thrive in increasingly knowledge-intensive economies. 


\section{For more information}

Contact: Francesco Avvisati (Francesco.Avvisati@oecd.org)

See: PISA 2015 Results (Volume I): Excellence and Equity in Education, PISA, OECD Publishing, Paris, http://dx.doi.org/10.1787/9789264266490-en.

PISA for Development www.oecd.org/pisa/aboutpisa/pisafordevelopment.htm.

Spaull, N. (2017), "Who makes it into PISA? Understanding the impact of PISA sample eligibility using Turkey as a case study (PISA 2003 - PISA 2012)", OECD Education Working Papers, No. 154, OECD Publishing, Paris, http://dx.doi.org/10.1787/41d175fc-en.

Coming next month: What are equitable school systems (not) doing?

This paper is published under the responsibility of the Secretary-General of the OECD. The opinions expressed and the arguments employed herein do not necessarily reflect the official views of OECD member countries.

This document and any map included herein are without prejudice to the status of or sovereignty over any territory, to the delimitation of international frontiers and boundaries and to the name of any territory, city or area.

This work is available under the Creative Commons Attribution-NonCommercial-ShareAlike 3.0 IGO (CC BY-NC-SA 3.0 IGO). For specific information regarding the scope and terms of the licence as well as possible commercial use of this work or the use of PISA data please consult Terms and Conditions on www.oecd.org. 